\title{
Active Component of Danshen (Salvia miltiorrhiza Bunge), Tanshinone I, Attenuates Lung Tumorigenesis via Inhibitions of VEGF, Cyclin A, and Cyclin B Expressions
}

\author{
Yu-Tang Tung, ${ }^{1}$ Hsiao-Ling Chen, ${ }^{2}$ Cheng-Yu Lee, ${ }^{3}$ Yu-Ching Chou, ${ }^{1}$ Po-Ying Lee, \\ Hsin-Chung Tsai, ${ }^{1,5}$ Yi-Ling Lin, ${ }^{1,6}$ and Chuan-Mu Chen ${ }^{1}$ \\ ${ }^{1}$ Department of Life Sciences, Agricultural Biotechnology Center, National Chung Hsing University, Taichung 402, Taiwan \\ ${ }^{2}$ Department of Bioresources and Molecular Biotechnology, Da-Yeh University, Changhwa 515, Taiwan \\ ${ }^{3}$ Department of Plant Industry, National Pingtung University of Science and Technology, Pingtung 912, Taiwan \\ ${ }^{4}$ Department of Surgery, National Taiwan University Hospital Yun-Lin Branch, Yun-Lin 640, Taiwan \\ ${ }^{5}$ Taichung Hospital, Department of Health, Taichung 403, Taiwan \\ ${ }^{6}$ Department of Surgery, Taichung Veterans General Hospital, Taichung 407, Taiwan
}

Correspondence should be addressed to Chuan-Mu Chen; chchen1@dragon.nchu.edu.tw

Received 7 September 2012; Accepted 5 March 2013

Academic Editor: Mei Tian

Copyright (C) 2013 Yu-Tang Tung et al. This is an open access article distributed under the Creative Commons Attribution License, which permits unrestricted use, distribution, and reproduction in any medium, provided the original work is properly cited.

\begin{abstract}
Tanshinone I (T1) and tanshinone II (T2) are the major diterpenes isolated from Danshen (Salvia miltiorrhiza Bunge). Three human lung adenocarcinoma cell lines, A549, CL1-0, and CL1-5, were treated with T1 and T2 for the in vitro antitumor test. Results showed that T1 was more effective than T2 in inhibiting the growth of lung cancer cells via suppressing the expression of VEGF, Cyclin A, and Cyclin B proteins in a dose-dependent manner. Moreover, a transgenic mice model of the human vascular endothelial growth factor- $\mathrm{A}_{165}\left(h V E G F-A_{165}\right)$ gene-induced pulmonary tumor was further treated with $\mathrm{T} 1$ for the in vivo lung cancer therapy test. T1 significantly attenuated hVEGF- $\mathrm{A}_{165}$ overexpression to normal levels of the transgenic mice (Tg) that were pretreated with human monocytic leukemia THP-1 cell-derived conditioned medium (CM). It also suppressed the formation of lung adenocarcinoma tumors $(16.7 \%$ ) compared with two placebo groups $(50 \%$ for Tg/Placebo and $83.3 \%$ for Tg/CM/Placebo; $P<0.01$ ). This antitumor effect is likely to slow the progression of cells through the $S$ and G2/M phases of the cell cycle. Blocking of the tumor-activated cell cycle pathway may be a critical mechanism for the observed antitumorigenic effects of T1 treatment on vasculogenesis and angiogenesis.
\end{abstract}

\section{Introduction}

According to statistics supplied by the Taiwanese Department of Health, pulmonary cancer is the most common invasive malignancy and the leading cause of cancer deaths in Taiwan [1]. Pulmonary cancer, according to the biocharacteristics and the clinical manifestation, can be divided into two gross types including small cell lung cancer and nonsmall cell lung cancer. According to the statistics of epidemiology in Taiwanese district, among patients with lung cancers, the ratio of patients of small cell lung cancer is only $12 \%-15 \%$ and the ratio of patients of nonsmall cell lung cancer is about $85 \%-88 \%$. The nonsmall cell lung cancer primarily includes pulmonary squamous cell carcinoma, pulmonary large cell lung carcinoma, and pulmonary adenocarcinoma [2]. Pulmonary adenocarcinoma induces a tumor resulted from cells classified as secretory cells including Clara cell, type II alveolar cells, and mucin producing cells. Pulmonary adenocarcinoma commonly occurs in the peripheral of lung (about 2/3) and the other $1 / 3$ of it starts proliferation from the center of lung [3]. Upon forming a tumor by pulmonary adenocarcinoma in a patient, it will cause distal metastasis to other organs including brain, kidney, liver, and bone in $80 \%$ of patients. Therefore, many researchers have searched for more effective treatments to cure pulmonary adenocarcinoma [4]. 
In the early stages of cancer, the out-of-control proliferation of cancer cells leads to a deficiency of both nutrients and oxygen that causes a large degree of cell death. Therefore, an inflammation response occurs, and hypoxia-inducible factor- $1 \alpha$ (HIF- $1 \alpha)$ is activated. The HIF- $1 \alpha$ activation induces secretion of a large quantity of vascular endothelial growth factor- $A_{165}\left(V E G F-A_{165}\right)$. The secreted VEGF-A $A_{165}$ binds to VEGFR2 receptor and activates a downstream signal that induces vasculogenesis $[5,6]$. When cancer cells secrete a large amount of VEGF-A ${ }_{165}$, vasculogenesis is induced so as to provide sufficient nutrition and oxygen to the tumor, thus increasing tumor growth rate. It is well known that the expression level of VEGF-A ${ }_{165}$ is positively related to the growth and spread of cancer cells [7]. Therefore, the development of medicines that target VEGF-A 165 is a popular topic of study.

Traditional medicine usually contains various bioactive phytochemicals with the chemoprevention and therapy of cancer [8]. Danshen (Salvia miltiorrhiza Bunge) is a traditional medicine that has been used in China for over a thousand years to treat various diseases, including coronary artery disease, cerebrovascular disease, heart disease, hepatitis, and cancer [9-11]. Over 40 tanshinone compounds have been isolated and identified from Danshen. Of these, tanshinone I (T1), tanshinone II (T2), and cryptotanshinone (CTS) are the three major diterpene compounds [11, 12], which possess anticancer properties [8]. Furthermore, T1 reduced the growth of leukemia [13-16], lung cancer [17], and breast cancer [18] in in vitro cell cultures via induction of apoptosis.

In this study, an expression vector carrying a mouse Clara cell secretory protein ( $m C C S P$ ) gene promoter and the human vegf- $A_{165}$ gene cDNA sequence was constructed. Then, the expression vector was introduced into the embryos of FVB mice by a microinjection process and the embryos were transplanted into the fallopian tubes of female mice. The embryos are allowed to develop into the newborn mice and the hVEGF- $\mathrm{A}_{165}$ is capable of expressing in the lung bronchus epidermal cells of the transgenic mice. The transgenic mouse carrying $h v e g f-A_{165}$ gene, which induces pulmonary tumor, was used as in vivo lung cancer therapy model.

$\mathrm{T} 1 \mathrm{had}$ antitumorigenic and antimetastatic effects in CL1-5-bearing SCID mice when coinjected with condition medium (CM) which is a serum-free medium with $24 \mathrm{~h}$ incubation with phorbol myristate acetate-treated human monocytic leukemia THP-1 cells [17]. Previous studies showed that the CM contains proinflammatory cytokines such as TNF- $\alpha$, IL-1, IL-8, and IL-12; anti-inflammatory cytokines such as TGF- $\beta$, IL-4, IL-10, and IL-13; and IL-6 with both proinflammatory and anti-inflammatory properties [19-23]. Previous reports have shown that the imbalance between proinflammatory and anti-inflammatory cytokines can influence neoplastic outcome [19]. Lee et al. [17] showed that the CM treatment alone would invoke inflammation and neovascularization and promote tumor growth due to the abundant proinflammatory cytokines. Thus, in this study a strain of human hvegf- $A_{165}$-induced lung tumorigenic transgenic mice was used to research the regulatory mechanism of $\mathrm{T} 1$ coinjected with $\mathrm{CM}$ against pulmonary adenocarcinoma.

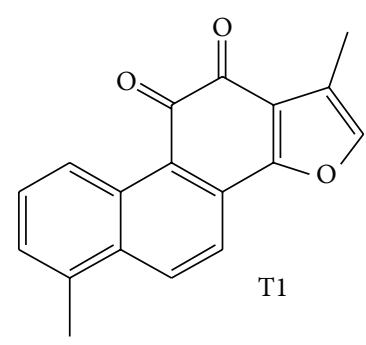

(a)

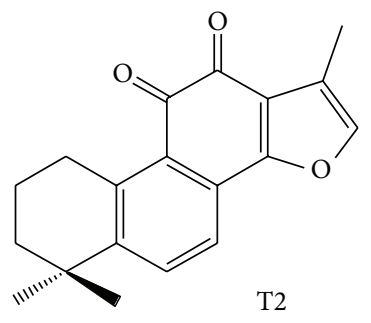

(b)

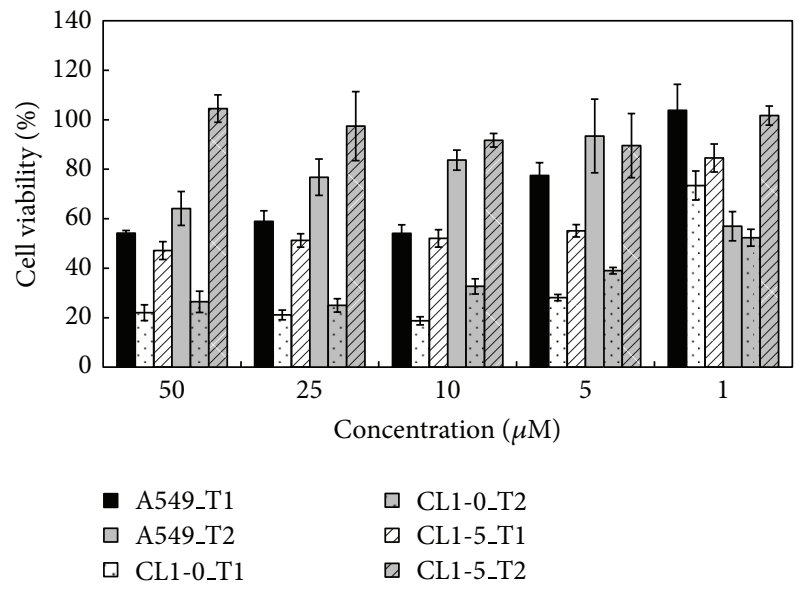

(c)
FIgURE 1: Active components of tanshinone I (T1) and tanshinone II (T2) extracted from a Chinese traditional medicine, Danshen (Salvia miltiorrhiza Bunge), and the cell viability of human lung cancer cell lines after T1 and T2 treatments. (a) Chemical structure of T1. (b) Chemical structure of T2. (c) Effects of T1 and T2 over a range of concentrations $(1,5,10,25$, and $50 \mu \mathrm{M})$ on the cell viability of A549, CL1-0, and CL1-5 cells after $24 \mathrm{~h}$ incubation.

\section{Methods}

2.1. Chemicals. Tanshinone I (1,6-dimethyl-phenanthro [1,2-b]furan-10,11-dione) (purity 99\%) and tanshinone II (1,6,6-trimethyl-6,7,8,9-tetrahydrophenanthro [1,2-b]furan10,11-dione) (purity 99\%) were obtained from Formosa Kingstone Bioproducts International (Taipei, Taiwan) (Figure 1). Tanshinones were isolated from the root of $S$. miltiorrhiza Bunge.

2.2. Cell Line. The human monocytic leukemia cell line THP1 (ATCC TIB 202; American Type Culture Collection) was grown in RPMI 1640 (Invitrogen Corp., Carlsbad, CA, USA) supplemented with $1.5 \mathrm{~g} / \mathrm{L} \mathrm{Na}_{2} \mathrm{HCO}_{3}, 4.5 \mathrm{~g} / \mathrm{L}$ glucose, and $10 \%$ fetal bovine serum (FBS). The cell line was incubated at $37^{\circ} \mathrm{C}$ in $5 \% \mathrm{CO}_{2}$. Before the experiments, THP-1 cells were pretreated with $3.2 \times 10^{7}$ mole $/ \mathrm{L}$ phorbol myristate acetate (Sigma-Aldrich Corp., St. Louis, MO, USA) for $24 \mathrm{~h}$. The preparation of conditioned medium (CM) derived from phorbol myristate acetate-pretreated THP-1 cells has been described previously [24]. Human lung adenocarcinoma cell lines, A549, CL1-0, and CL1-5 cells, were cultured in 
Dulbecco's modified Eagle's medium (DMEM) supplemented with $10 \% \mathrm{FBS}$. Cells were incubated at $37^{\circ} \mathrm{C}$ in $5 \% \mathrm{CO}_{2}$.

2.3. Cell Viability on Tumor Cells by MTT Assay. To measure the cytotoxicity of tanshinone I and tanshinone II on cell proliferation, A549, CL1-0, and CL1- 5 cells $\left(2 \times 10^{5}\right.$ cells/well $)$ were seeded into a 96 -well plate in triplicate and preincubated for $3 \mathrm{~h}$ to allow cell adherence. First, $200 \mu \mathrm{L}$ of fresh medium containing various concentrations $(1,5,10,25$, and $50 \mu \mathrm{M})$ of tanshinone I and tanshinone II was added into the cultures and incubated at $37^{\circ} \mathrm{C}$ for 24,48 , and $72 \mathrm{~h}$ under humidified air containing 5\% $\mathrm{CO}_{2}$. Following the removal of the medium from the wells, $100 \mu \mathrm{L}$ of tetrazolium salt solutions ( $1 \mathrm{~mL}$ MTT in $10 \mathrm{~mL}$ DMEM) was added. After $4 \mathrm{~h}$ of incubation at $37^{\circ} \mathrm{C}$, the medium was removed and $100 \mu \mathrm{L}$ of DMSO was added to dissolve the formazan crystals. Absorbance was measured in an enzyme-linked immunosorbent assay (ELISA) reader at $570 \mathrm{~nm}$. The cell viability ratio (\%) was calculated from the following equation: \% viability = (absorbance of test sample/absorbance of control) $\times 100$.

2.4. Transgenic Mouse Production and Validation. The mccsp-hVEGF- $\mathrm{A}_{165}$-sv40 transgenic mice were generated by pronuclear microinjection. A 1975-bp transgene fragment, consisting of $m C C S P$ promoter, $h V E G F-A_{165}$ cDNA, and SV40 poly(A) signal sequence, was obtained from the plasmid with NruI-SapI double-digestion. The purified transgene was microinjected into the male pronuclei of fertilized eggs from superovulated female mice and transferred to recipient pseudopregnant females [22]. To detect the hVEGF- $\mathrm{A}_{165}$ transgene in transgenic mice with a homozygous (hVEGF- $\mathrm{A}_{165}{ }^{+/+}$) or heterozygous (hVEGF- $\mathrm{A}_{165}{ }^{+-}$) genotype, the mice were rapidly screened for the foreign gene by PCR analysis [25]. The exogenic human VEGF-A $\mathrm{A}_{165}$ protein expression levels in homozygous $\left(\right.$ hVEGF- $\mathrm{A}_{165}{ }^{+/+}$) or heterozygous (hVEGF- $\mathrm{A}_{165}{ }^{+-}$) transgenic mice were also detected by western blot [25]. In this study, we used the homozygous (hVEGF- $\mathrm{A}_{165}{ }^{+/+}$) genotype to evaluate the anticancer effects of T1.

2.5. Animals. The transgenic mice and wild-type FVB strain mice were sustained on a standard laboratory diet and distilled water ad libitum and kept on a 12-hour light/dark cycle at $22 \pm 2^{\circ} \mathrm{C}$. This study was conducted according to institutional guidelines and approved by the Institutional Animal Care and Utilization Committee of National Chung Hsing University, Taiwan (IACUC No. 96-83). For the examination of both $V E G F$ expression and pulmonary function, the transgenic mice with the homozygous genotype (hVEGF$\left.\mathrm{A}_{165}{ }^{+/+}\right)$were normally distributed to three groups $(n=6)$ and treated as follows: (1) PBS alone (Tg/Placebo group), (2) $\mathrm{CM}$ alone (Tg/CM/Placebo group), and (3) T1 (1 mg/kg body weight) suspended in $\mathrm{CM}(\mathrm{Tg} / \mathrm{CM} / \mathrm{T} 1$ group). Three groups were injected intraperitoneally (i.p.) three times a week. In addition, wild-type FVB strain mice $(n=6)$ were used as a normal control group. Experimental mice were sacrificed at the age of 10 months old after stimulation by $\mathrm{CM}$ during months $2-4$ and $6-10$ and then receiving $\mathrm{T} 1$ or placebo administration at months 6-10. Pulmonary tissues were collected for pathological histology, immunohistochemical (IHC) staining [26, 27], and RNA [28] and protein extraction.

2.6. Measurement of Airway Hyperresponsiveness (AHR). To evaluate AHR in the Tg/Placebo, Tg/CM/Placebo, and $\mathrm{Tg} / \mathrm{CM} / \mathrm{T} 1$ groups, bronchial provocation tests were performed using methacholine. First, the basal pulmonary function was measured; then, saline and methacholine $(12.5 \mathrm{mg} / \mathrm{mL})$ were converted to aerosols using a nebulizer; finally, the mice inhaled the aerosolized compounds five times through a Rosenthal-French dosimeter. Three minutes later, a pulmonary function test was performed. The pulmonary function at each step was measured 30 times with a portable microspirometer, and the enhanced pause (penh) values were selected as the pulmonary function value [25].

2.7. Pathological Histology. Lung tissue was fixed in $10 \%$ buffered formaldehyde ( $\mathrm{pH}$ 7.0), embedded with paraffin, sectioned into $3 \mu \mathrm{m}$ sections, and examined using hematoxylin and eosin (H\&E) staining as described previously $[29,30]$.

2.8. Immunohistochemistry (IHC) Staining. Formaldehydefixed and paraffin-embedded sections were cut to a thickness of $5 \mu \mathrm{m}$, deparaffinized and rehydrated in a gradient of alcoholic solutions, and then treated with boiling water for 15 minutes. The sections were incubated in 3\% hydrogen peroxide for $10 \mathrm{~min}$ to block endogenous peroxidase activity and then incubated overnight at $4^{\circ} \mathrm{C}$ with primary rabbit monoclonal antibody against $\mathrm{hVEGF-A}$ using a $1: 40$ working dilution. For antigen retrieval, the sections were immunostained with the VECTASTAIN ABC kit (Universal, Vector Lab., Burlingame, CA, USA) in accordance with the manufacturer's specifications. Diaminobenzidine (DAB) was used for stain development, and the sections were counterstained with hematoxylin [31]. The negative control consisted of substituting normal serum for primary antibody.

2.9. Real-Time RT-PCR. Total RNA was extracted from lung tissue using Trizol reagent (Invitrogen, Carlsbad, CA, USA), as specified by the manufacturer. The total RNA $(2 \mu \mathrm{g})$ was then resuspended in $9 \mu \mathrm{L}$ of diethylpyrocarbonate-(DEPC-) treated water, and the first strand of CDNA was synthesized with random primers using ImProm-II reverse transcriptase (Promega, USA) in a total volume of $20 \mu \mathrm{L}$. The reaction was carried out at $42^{\circ} \mathrm{C}$ for $1 \mathrm{~h}$. For further PCR amplification, an aliquot $(1: 10)$ of the RT product was adjusted to contain $0.1 \mu \mathrm{g}$ of each primer, and additional buffer was added to a total volume of $20 \mu \mathrm{L}$. RT-PCR was performed in a Thermal Cycler 2720. Real-time RT-PCR was performed using SYBR Green in a Rotor-Gene 6000 [26]. To evaluate gene expression, realtime RT-PCR was performed on 6 genes (nrp-1, $k d r, m m p 2$, egfr, erk2, and survivin) using cDNA from pulmonary tissue. The cDNA of $\beta$-actin was used as an internal control.

2.10. Western Blotting. CL1-0 cells were seeded on a $10 \mathrm{~cm}$ dish for $2 \mathrm{~h}$; afterward, the cells were pretreated with $\mathrm{T} 1$ 


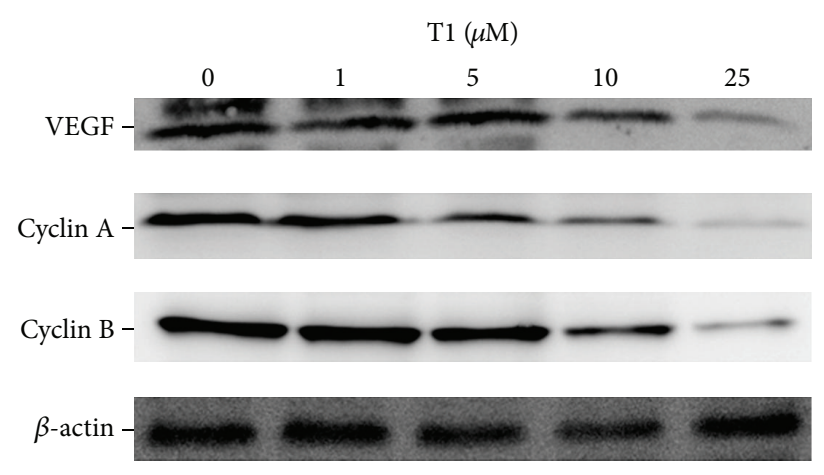

(a)

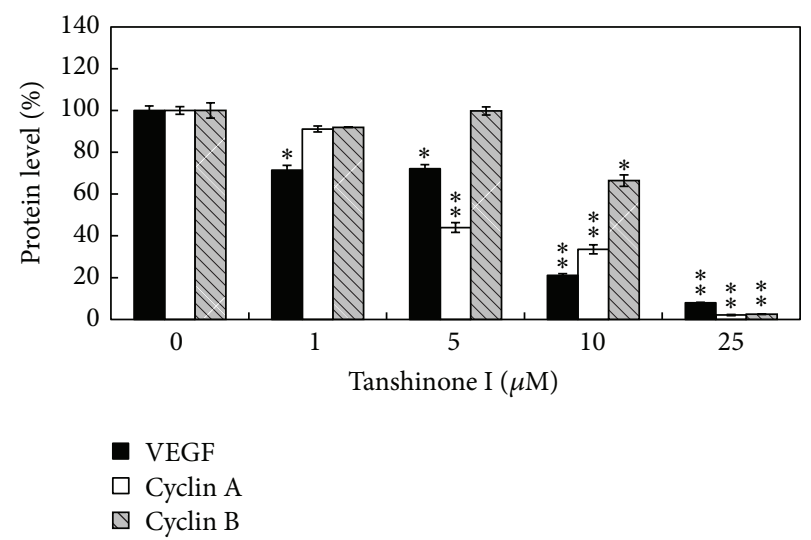

(b)

Figure 2: Expressions of VEGF, Cyclin A, and Cyclin B protein in CL1-0 cells treated with T1 after $24 \mathrm{~h}$ incubation. (a) Western blot analysis of VEGF, Cyclin A, and Cyclin B protein expressions in CL1- 0 cells after being treated with different concentrations of T1 ( 0 , $1,5,10$, and $25 \mu \mathrm{M}$ ) for $24 \mathrm{~h}$. (b) The quantification data of protein expression levels under different concentrations of $\mathrm{T} 1$ treatment.

$(1,5,10$, and $25 \mu \mathrm{M})$ for $24 \mathrm{~h}$. The expressions of VEGF, Cyclin A, and Cyclin B proteins were measured by western blotting. Pulmonary tissues were homogenized in $500 \mu \mathrm{L}$ of RIPA buffer ( $5 \mathrm{mM}$ Tris- $\mathrm{HCl} \mathrm{pH} 7.4,0.15 \mathrm{M} \mathrm{NaCl}, 1 \%$ NP40, $0.25 \%$ sodium deoxycholate, $5 \mathrm{mM}$ EDTA, and $1 \mathrm{mM}$ ethylene glycol-bis (2-aminoethyl-ether)-N, N, N, N-tetraacetic acid). The homogenates were centrifuged at $12,000 \mathrm{~g}$ for 30 minutes at $4^{\circ} \mathrm{C}$. Protein $(40 \mu \mathrm{g})$ was then separated by SDS-PAGE in $10 \%$ polyacrylamide and electrotransferred to polyvinylidene difluoride membranes. The membranes were incubated in blocking solution (5\% BSA) at room temperature for $2 \mathrm{~h}$. The membranes were then incubated with primary antibody (VEGF-A, ERK2, Cyclin A, Cyclin $\mathrm{B}$, and GAPDH) overnight at $4^{\circ} \mathrm{C}$. After washing, the membranes were incubated with a goat anti-rabbit IgG peroxidaseconjugated secondary antibody directed against the primary antibody. The membranes were developed using an enhanced chemiluminescence western blot detection system as described previously [32].

2.11. Statistical Analysis. Experimental values are expressed as the mean \pm standard error (SE). All data were analyzed

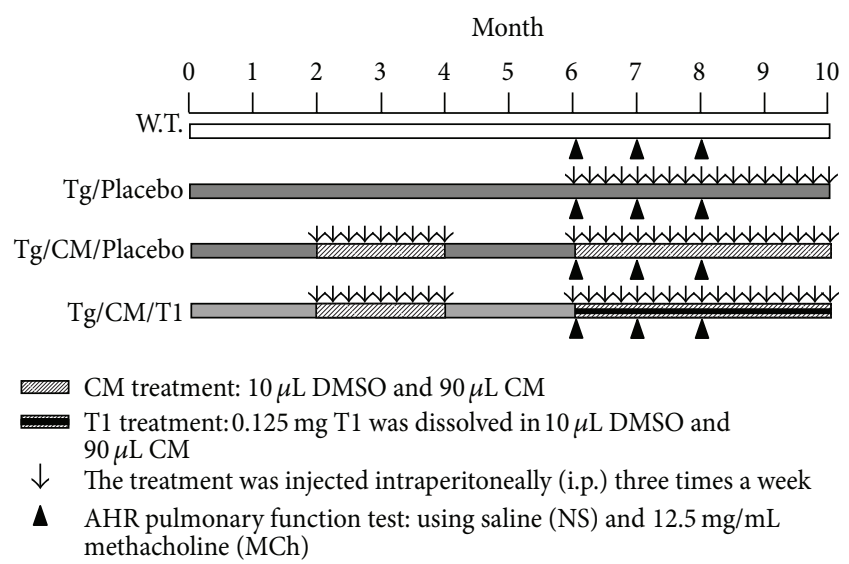

(a)

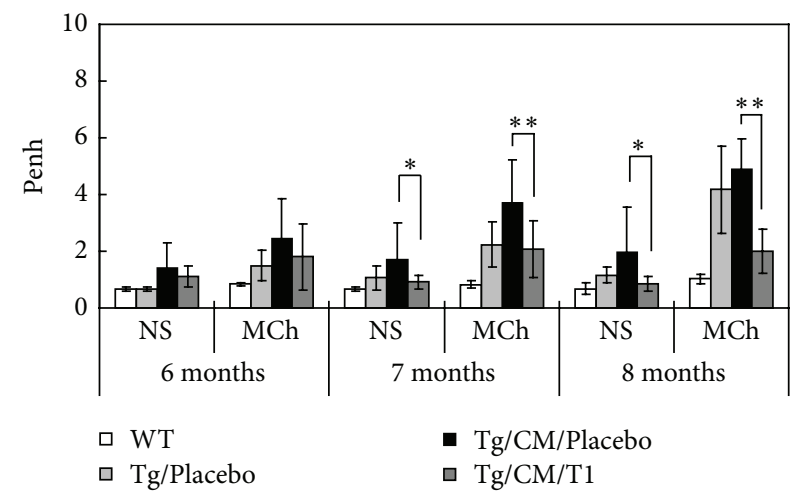

(b)

FIGURE 3: The schedule of animal trials and the effect of tanshinone I on airway hyperresponsiveness (AHR) parameters of pulmonary function. (a) The experimental designation for evidence-based lung tumorigenesis attenuation in animal trial. T1 was injected intraperitoneally (i.p.) at $1 \mathrm{mg} / \mathrm{kg}$ b.w. three times a week. Mice were sacrificed at 10 months of age after $\mathrm{T} 1$ administration for 4 months. (b) The Penh (enhanced pause) is a dimensionless value that represents a function of the proportion of maximal expiratory to maximal inspiratory box pressure signals and of the timing of expiration. Data were presented as mean \pm SEM $(n=6)$. The AHR was measured at 6, 7, and 8 months. WT: wild-type FVB mice; Tg/Placebo: hVEGF- $\mathrm{A}_{165}{ }^{+/+}$transgenic mice without $\mathrm{T} 1$ supplement; Tg/CM/Placebo: condition medium-treated transgenic mice without $\mathrm{T} 1$ supplement; $\mathrm{Tg} / \mathrm{CM} / \mathrm{T} 1$ : condition medium treated transgenic mice with T1 supplement; NS: normal saline; MCh: methacholine.

using $t$-tests. Statistical significances are presented as $P<$ $0.05\left(^{*}\right)$ or $P<0.01\left(^{* *}\right)$.

\section{Results}

3.1. Effects of T1 and T2 on Cancer Cell Viability. A549, CL1-0, and CL1-5 cells, which are human lung adenocarcinoma cell lines, were treated with the major active components isolated from Danshen, tanshinone I (T1; Figure 1(a)) and tanshinone II (T2; Figure 1(b)) at concentrations of $1,5,10,25$, and $50 \mu \mathrm{M}$ for 24,48 , and $72 \mathrm{~h}$. This treatment decreased the cell viability in a concentration-dependent manner when compared with 

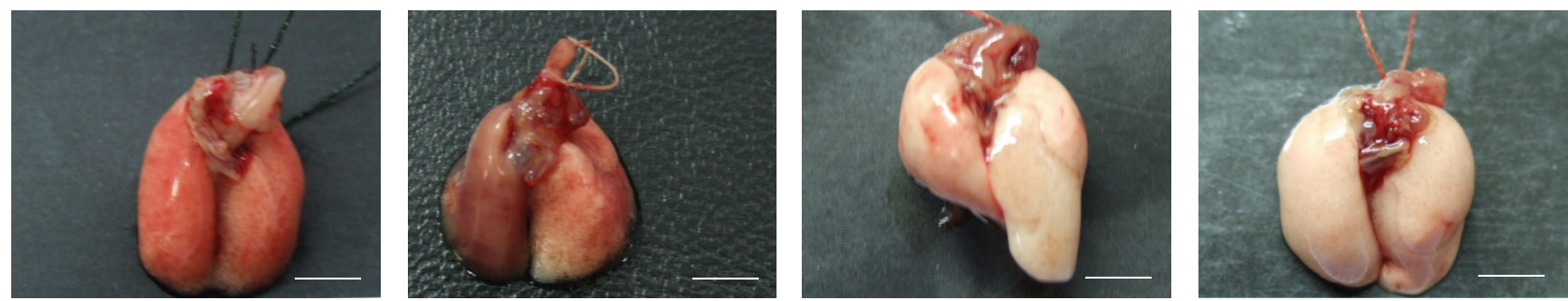

(a)

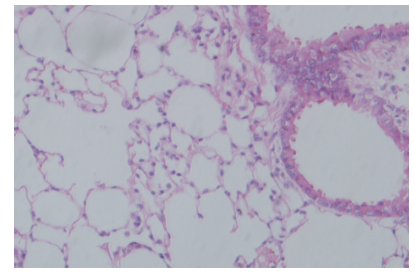

Wild type

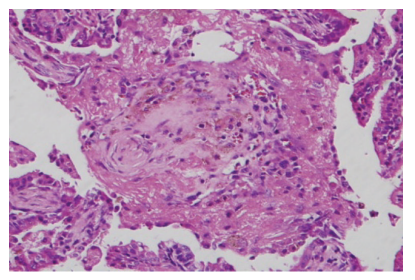

$\mathrm{Tg} /$ Placebo

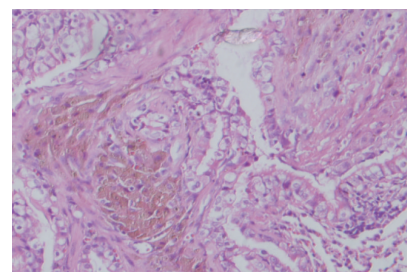

$\mathrm{Tg} / \mathrm{CM} /$ Placebo

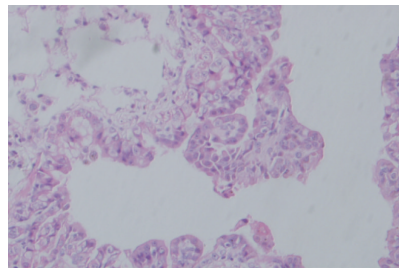

$\mathrm{Tg} / \mathrm{CM} / \mathrm{T} 1$

(b)

FIgURE 4: Photographs of whole lungs (a) and stained histopathologic slides of lung tissues (b) from wild-type-FVB mice, hVEGF-A ${ }_{165}^{+/+}$ transgenic mice (Tg/Placebo), condition medium-treated transgenic mice (Tg/CM/Placebo), and condition medium treated transgenic mice with $\mathrm{T} 1$ supplement $(\mathrm{Tg} / \mathrm{CM} / \mathrm{T} 1)$ groups. Tissues from the $\mathrm{Tg} / \mathrm{CM} / \mathrm{T} 1$ group were taken from 10-month-old hVEGF- $\mathrm{A}_{165}$ overexpressing transgenic mice after Tl administration for 4 months. The tissue sections were stained with H\&E and photographed at 200x magnifications. Scale bar $=5 \mathrm{~mm}$.

TABLE 1: Lung tumorigenesis frequency of wild type, $\mathrm{Tg} / \mathrm{Placebo}, \mathrm{Tg} / \mathrm{CM} / \mathrm{Placebo}$, and $\mathrm{Tg} / \mathrm{CM} / \mathrm{T} 1$ groups in the mouse lung tissues $(n=6)$ using histopathological image analysis.

\begin{tabular}{|c|c|c|c|c|}
\hline Variable & Wild type & Tg/Placebo & Tg/CM/Placebo & $\mathrm{Tg} / \mathrm{CM} / \mathrm{T} 1$ \\
\hline Normal & $100(100 \%)$ & $0(0 \%)$ & $0(0 \%)$ & $2(33.3 \%)$ \\
\hline Cyst & $0(0 \%)$ & $2(33.3 \%)$ & $0(0 \%)$ & $3(50 \%)$ \\
\hline Damaged alveoli & $0(0 \%)$ & $3(50 \%)$ & $4(66.7 \%)$ & $3(50 \%)$ \\
\hline Mild emphysematous change & $0(0 \%)$ & $2(33.3 \%)$ & $0(0 \%)$ & $3(50 \%)$ \\
\hline Prominent emphysematous change & $0(0 \%)$ & $3(50 \%)$ & $3(50 \%)$ & $1(16.7 \%)$ \\
\hline Hemosiderin-laden macrophages in alveoli & $0(0 \%)$ & $3(50 \%)$ & $5(83.3 \%)$ & $1(16.7 \%)$ \\
\hline Old hemorrhage & $0(0 \%)$ & $1(16.7 \%)$ & $2(33.3 \%)$ & $1(16.7 \%)$ \\
\hline Moderate lymphocytic infiltration & $0(0 \%)$ & $2(33.3 \%)$ & $4(66.7 \%)$ & $1(16.7 \%)$ \\
\hline Marked chronic lymphoid infiltration & $0(0 \%)$ & $2(33.3 \%)$ & $4(66.7 \%)$ & $1(16.7 \%)$ \\
\hline Neoplasm & $0(0 \%)$ & $1(16.7 \%)$ & $1(16.7 \%)$ & $0(0 \%)$ \\
\hline Lymphoma & $0(0 \%)$ & $1(16.7 \%)$ & $1(16.7 \%)$ & $0(0 \%)$ \\
\hline Adenocarcinoma & $0(0 \%)$ & $3(50 \%)$ & $5(83.3 \%)$ & $1(16.7 \%)$ \\
\hline
\end{tabular}

controls (Figure $1(\mathrm{c})$ ). In MTT assay, T1 was more effective than $\mathrm{T} 2$, and the $\mathrm{IC}_{50}$ values of $\mathrm{T} 1$ were $8.9,1.8$, and $2.0 \mu \mathrm{M}$ for A549, CL1-0, and CL1-5 cells at $24 \mathrm{~h}$, respectively. Of these cancer cells, T1 was able to successfully inhibit the growth of CL1-0 cells.

3.2. T1 Suppressed VEGF, Cyclin A, and Cyclin B Protein Expressions in CL1-0 Lung Cancer Cells. As shown in Figure 2(a), T1 inhibited the expressions of VEGF, Cyclin A, and Cyclin B protein in a dose-dependent manner. Approximately $77 \%, 60 \%$, and $25 \%$ reductions of VEGF, Cyclin A, and Cyclin B protein were observed at $10 \mu \mathrm{M}$, as determined with densitometry analysis (Figure 2(b)). At concentrations of up to $10 \mu \mathrm{M}$, T1 could almost completely inhibit the expression of Cyclin A, and Cyclin B proteins in CL1-0 cells. Thus, T1 warrants further development as a cancer-prevention agent.

3.3. Effect of $T 1$ on AHR Parameters of Pulmonary Function. A strain of transgenic mice carrying hvegf- $A_{165}$ gene, which induces pulmonary tumor, was used as an in vivo lung cancer model for test of $\mathrm{T} 1$ therapeutic effects. The animal trials timeline was shown in Figure 3(a). It is well known that AHR is an important measure of pulmonary function, and hyperresponsiveness to methacholine (MCh) is an indicator of lung function. In this study, the AHR was measured at 6,7 , and 8 months. At 6 months, penh values for the wild type, Tg/Placebo, Tg/CM/Placebo and $\mathrm{Tg} / \mathrm{CM} / \mathrm{T} 1$ groups treated with methacholine were $0.84,1.50$, 

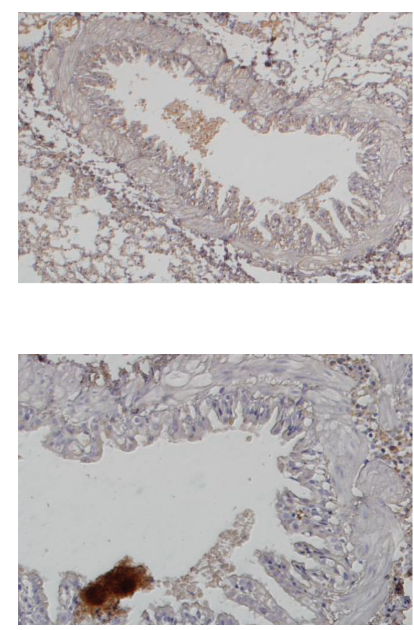

Wild type
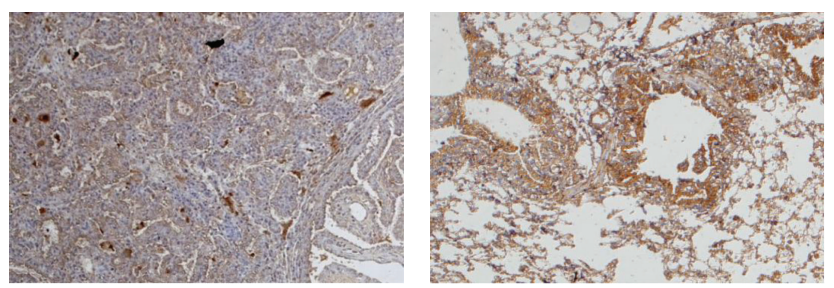

(a)

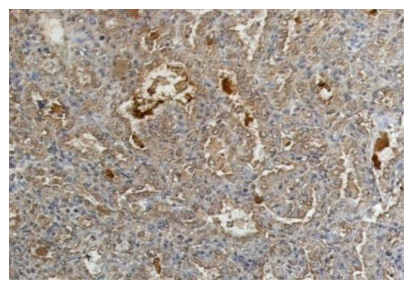

$\mathrm{Tg} /$ Placebo

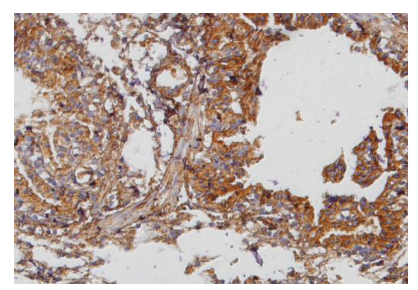

$\mathrm{Tg} / \mathrm{CM} /$ Placebo
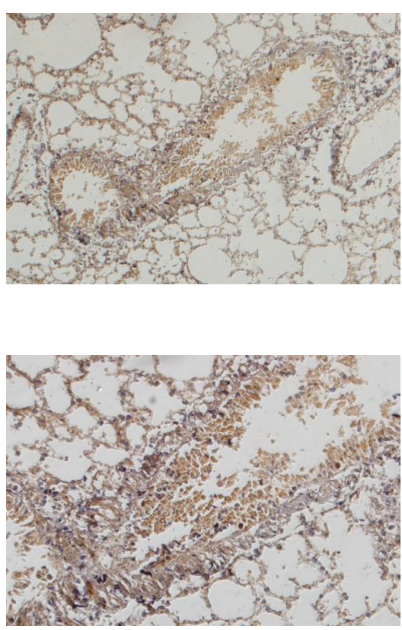

$\mathrm{Tg} / \mathrm{CM} / \mathrm{T} 1$

(b)

FIGURE 5: Immunohistochemical (IHC) staining of VEGF expression in lung tissues of the wild-type FVB mice, $\mathrm{hVEGF} \mathrm{A}_{165}{ }^{+/+}$transgenic mice (Tg/Placebo), Tg/CM/Placebo, and Tg/CM/T1 groups. Tissues were taken from 10-month-old experimental mice after T1 or PBS administration for 4 months. Sections were stained with primary rabbit monoclonal antibody against human VEGF-A using a 1: 40 working dilution. Upper panels were observed under 100x magnifications, and lower panels were observed under 200x magnifications.

2.46 , and 1.80 , respectively; at 7 months, they were 0.82 , $2.24,3.70$, and 2.07 , respectively; and at 8 months, they were $1.03,4.17,4.87$, and 2.01 , respectively (Figure $3(\mathrm{~b})$ ). Thus, the $\mathrm{Tg} / \mathrm{CM} / \mathrm{T} 1$ experimental group treated with $1 \mathrm{mg} / \mathrm{kg}$ b.w. of T1 showed significantly lower penh values when compared to $\mathrm{Tg} / \mathrm{CM} /$ Placebo group $(P<0.01)$.

3.4. Effect of $\mathrm{T1}$ on Pathological Histology. Figure 4 and Table 1 showed that various degrees of progressing pulmonary tumors were formed in the transgenic mice and primarily consisted of neoplasms growing on the periphery of the pulmonary alveolus and adenomas growing adjacent to the lung bronchus. In the pulmonary alveolus of the lung bronchus of transgenic mice, some large-grained pink cells were clearly visible. These pink cells were identified as macrophages, which are indicative of an inflammation response (Figure 4). These results show that hVEGF-A $\mathrm{A}_{165}$ is capable of promoting vascular permeability and an inflammation response. Furthermore, CM treatment alone invoked inflammation and neovascularization as well as promoted lung adenocarcinoma growth $(83.3 \% ; 5 / 6)$ compared with $\mathrm{Tg}$ alone $(50 \% ; 3 / 6)$, which may be due to various proinflammatory cytokines. Treatment with $\mathrm{T} 1 \mathrm{might}$ have an effect on the balance of proinflammatory and anti-inflammatory cytokines by eliminating the proinflammatory cytokines and then significantly reduced lung tumor growth $(16.7 \% ; 1 / 6)$ as shown in Table 1.

Angiogenesis is an important factor in the formation of tumors as well as in tumor growth, invasion, and metastasis. VEGF promotes the initial formation of new blood vessels (vasculogenesis) and plays a vital role in the growth and expansion of these new blood vessels (angiogenesis). Using IHC staining, we found that hVEGF was overexpressed in Clara cells of lung tissue from the $\mathrm{Tg} /$ Placebo group
(Figure 5). Clearly, $\mathrm{Tg} / \mathrm{CM} /$ Placebo group significantly elevated VEGF overexpression in Clara cells compared with the $\mathrm{Tg} / \mathrm{Placebo}$ group. Interestingly, the treatment with $\mathrm{T} 1$ ( $1 \mathrm{mg} / \mathrm{kg}$ b.w.) significantly blocked VEGF overexpression in Clara cells when compared to the $\mathrm{Tg} / \mathrm{CM} /$ Placebo group. These results indicate that $\mathrm{T} 1 \mathrm{can}$ reduce hVEGF overexpression, which could in turn eliminate the formation and growth of new blood vessels. This is a possible explanation for how T1 can effectively block tumor growth, invasion, and metastases.

3.5. T1 Causes Suppression of Tumor-Formation Signal Genes. The mRNA expression patterns of $n r p-1, k d r, m m p 2$, egfr, erk2, and survivin in the $\mathrm{Tg} / \mathrm{Placebo}, \mathrm{Tg} / \mathrm{CM} /$ Placebo, and $\mathrm{Tg} / \mathrm{CM} / \mathrm{Tl}$ groups were assessed using real-time RT-PCR (Figure 6). T1 did not regulate mCCSP promoter in our internal test (see Figure S1 in Supplementary Material available online at http://dx.doi.org/10.1155/2013/319247); thus T1 directly effected VEGF expression. Furthermore, when compared to $\mathrm{Tg} /$ Placebo group, CM treatment alone increased the expression of mmp2 $(P<0.05)$, which is believed to be involved in tumor angiogenesis due to its matrixdegrading capacity. However, in this study, treatment with T1 normalized the expression of $m m p 2$. In addition, CM treatment alone markedly increased the mRNA levels of erk2 $(P<0.05)$, which is involved in the regulation of different cellular processes, from apoptosis to cell proliferation and differentiation. We observed a statistically significant decrease in the levels of activated erk 2 in the $\mathrm{Tg} / \mathrm{CM} / \mathrm{T} 1$ group in comparison with $\mathrm{Tg} / \mathrm{CM} /$ Placebo group.

3.6. T1 Causes Suppression of Cell Cycle Progression Signaling Pathways. Western blotting showed that VEGF, Cyclin A, and Cyclin $\mathrm{B}$ were downregulated in the $\mathrm{Tg} / \mathrm{CM} / \mathrm{T} 1$ group 


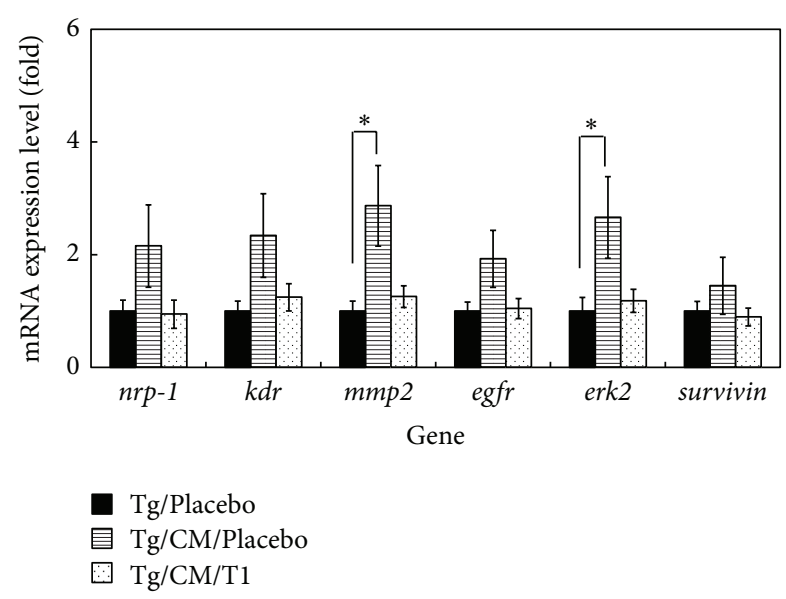

FIGURE 6: Validations of mRNA expression levels of $k d r, n r p-1$, $m m p 2$, egfr, erk2, and survivin in the lung tissues of Tg/Placebo, $\mathrm{Tg} / \mathrm{CM} / \mathrm{Placebo}$, and $\mathrm{Tg} / \mathrm{CM} / \mathrm{T} 1$ mice groups by real-time RT-PCR. A house keeping gene, $\beta$-actin, was used as an internal control. The quantitative mRNA expression levels based on three independent repeat experiments of real-time RT-PCR are calculated as mean \pm $\operatorname{SEM}(n=6) .{ }^{*} P<0.05$ versus Tg group.

when compared with the $\mathrm{Tg} / \mathrm{CM} /$ Placebo group (Figures 7(a) and $7(b))$. A possible reason for this cell cycle effect is the reduction of Cyclin $\mathrm{A}$, and Cyclin $\mathrm{B}$ that are regulators of the $S$ and G2/M phases, respectively. T1-induced inhibition of Cyclins A and B likely decreases the progression of cells through $S$ and $G 2 / M$ phases. These results indicate that the proteins involved in the $S$ to $M$ phase transition in $\mathrm{Tg} / \mathrm{CM} /$ Placebo group were suppressed by $\mathrm{T} 1$ treatment. Moreover, we have found that treatment with T1 dramatically decreases tumor formation in 10-month-old hVEGF-A 165 overexpressing transgenic mice compared with CM treatment alone (Table 1). These results suggest that $\mathrm{T} 1$ treatment significantly reduced the tumor formation due to downregulation of cancer cell cycle.

\section{Discussion}

Earlier studies have shown that Danshen possesses potent anti-inflammatory, antitumorigenic, and antimetastatic effects [17]. T1, one of the major diterpenes isolated from Danshen, shows cytotoxic effects on colon, ovary, lung, and oral cancer cell lines [33]. Furthermore, T1 has been shown to significantly inhibit pulmonary cancer cell migration, invasion, and gelatinase activity in vitro and to reduce metastasis, angiogenesis, and tumorigenesis in vivo [17]. In this study, we demonstrated that $\mathrm{T} 1$ slowed the inhibition of CL1-0 lung cancer cell proliferation by decreasing the expressions of VEGF, Cyclin A, and Cyclin B protein in a dose-dependent manner (Figure 2); thus T1 warrants further development as an antiangiogenic agent in the treatment of lung cancer. Furthermore, Nizamutdinova et al. [34] demonstrated $10 \mathrm{mg} / \mathrm{kg}$ T1 did not have any toxic and could markedly inhibited breast tumor growth. Lee et al. [17] revealed $0.3 \mathrm{mg} / \mathrm{kg} /$ day $\mathrm{T} 1$ significantly inhibited tumor

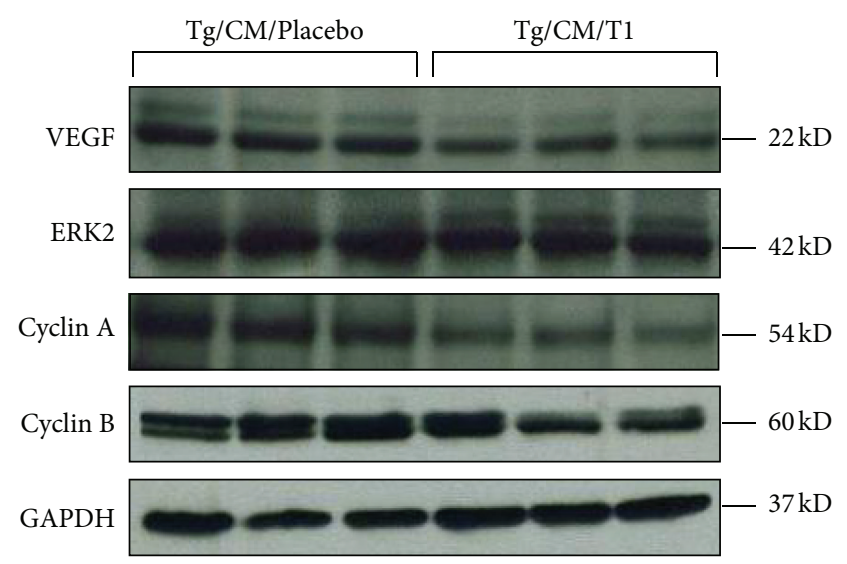

(a)

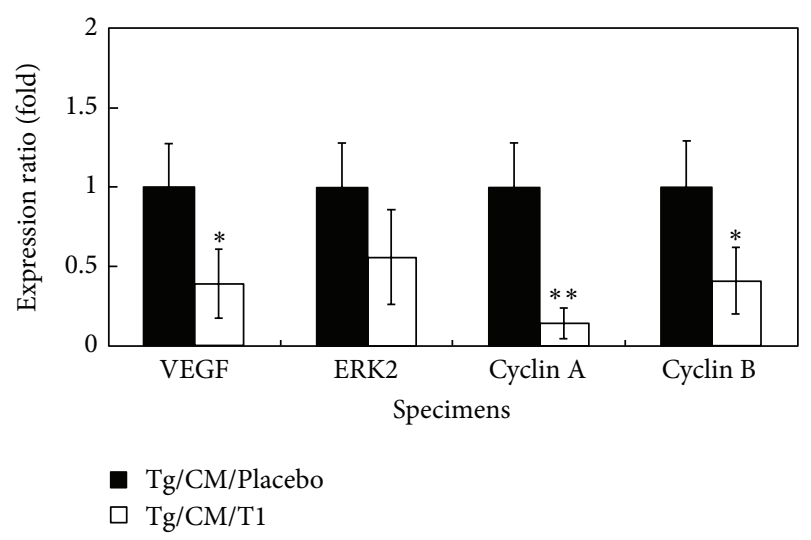

(b)

Figure 7: Protein expression levels of VEGF-A, ERK2, Cyclin A, and Cyclin B in the lung tissues of Tg/CM/Placebo and Tg/CM/T1 groups analyzed by western blots (a) and quantitative assay (b). GAPDH was used as an internal control. Protein expression was quantified as mean \pm SEM $(n=6)$ from three independent repeat experiments. ${ }^{*} P<0.05$ or ${ }^{* *} P<0.01$ versus $\mathrm{Tg} / \mathrm{CM} / \mathrm{Placebo}$ group.

vascularity and fewer tumor metastases in the lung. In addition, we used 10-month-old transgenic mice carrying the mccsp-hVEGF-A 165 -sv40 poly(A) transgene, which overexpresses lung-specific hVEGF- $\mathrm{A}_{165}$, to serve as an animal model treatment with $1 \mathrm{mg} / \mathrm{kg}$ b.w. T1 to research the regulatory mechanism of $\mathrm{T} 1$ in pulmonary cancer. We found that $\mathrm{CM}$ treatment alone promoted tumor growth. However, 10-month-old hVEGF-A 165 overexpressing transgenic mice showed a dramatic decrease in solid tumor formation following a 4-month treatment with $\mathrm{T} 1$ three times a week at $1 \mathrm{mg} / \mathrm{kg}$ b.w. compared with CM treatment alone. Histological examination also showed that treatment with T1 reduced pulmonary tumor formation and inflammation in $\mathrm{hVEGF}-\mathrm{A}_{165}$-overexpressing transgenic mice compared with the Tg/CM/Placebo group (Figure 4). Eberly et al. [35] demonstrated that pulmonary function is a predictor of lung cancer mortality. Thus, our results of AHR parameter detections further demonstrated that treatment with $\mathrm{T} 1 \mathrm{in}$ VEGF-A165 overexpressing transgenic mice could effectively 


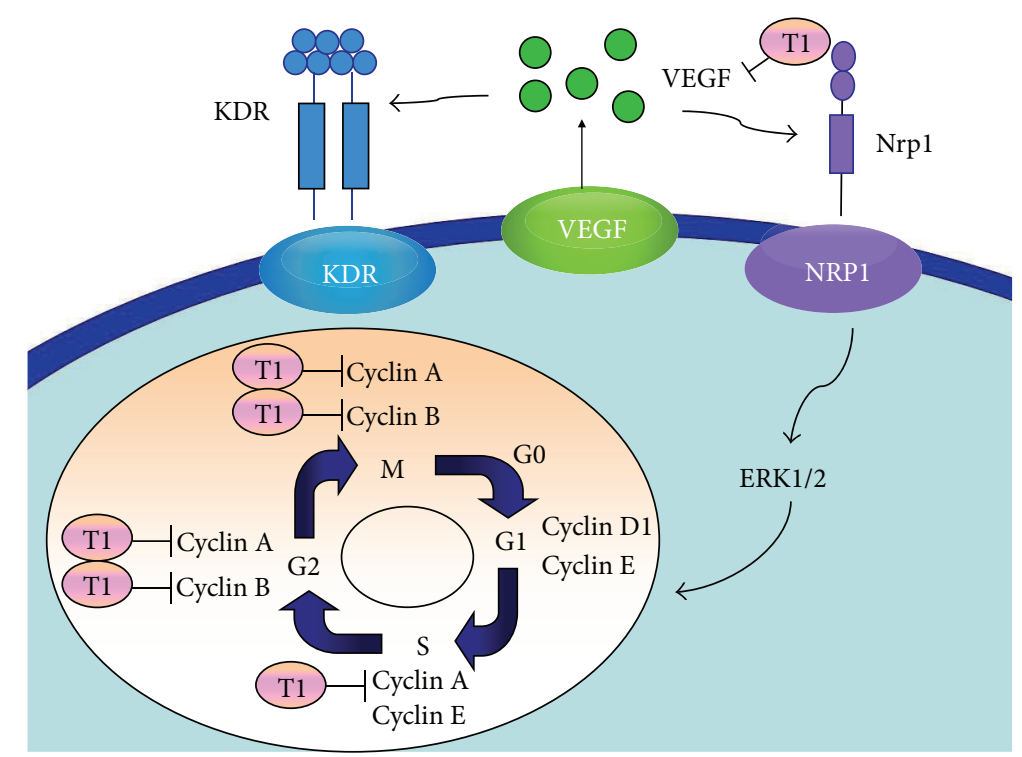

Figure 8: Proposed mechanism of the T1 regulatory pathways in lung tumorigenesis of VEGF- $\mathrm{A}_{165}$ overexpressed transgenic mice. The effects of $\mathrm{T} 1$ on lung tumor formation are hypothesized to occur through the cell cycle signaling. The diagram shows that T1 might inhibit the expressions of VEGF- $\mathrm{A}_{165}$ during signal transduction, as well as reductions of Cyclin A and Cyclin B during S and G2/M cell cycle stages.

reduce pulmonary function damage that may decrease the incidence of lung cancer.

In the initial stages of cancer, cells keep proliferating and leading to both nutrient and oxygen deficiencies that result in a large proportion of cell death. When cancer cells secrete a large amount of VEGF- $\mathrm{A}_{165}$, vasculogenesis is induced so as to avail sufficient nutrients and oxygen to the tumor, thus increasing the tumor growth rate [7]. The growth of a solid tumor is dependent on angiogenesis; thus suppression of tumor blood vessel formation offers a new option for the prevention and treatment of cancer. Using IHC staining, we found that $\mathrm{T} 1$ reduced VEGF overexpession in Clara cells when compared to Tg/CM/Placebo group (Figure 5). This reduction in VEGF overexpression has an impact on vasculogenesis and angiogenesis and is a vital factor in tumor formation, growth, invasion, and metastasis. Nizamutdinova and his colleagues [36] have shown that T1 effectively inhibited TNF- $\alpha$-induced VEGF production and VEGF-mediated tumor formation. In this study, we also found that treatment with T1 effectively decreased the expression of VEGF, thus demonstrating its utility as an antiangiogenic agent for the treatment of pulmonary cancer.

Recently, there has been an extensive evaluation of the use of plants and their phytochemicals in the treatment of cancers. In particular, active phytochemicals that function as cell cycle modulators are gaining widespread attention [37]. In this study, we have confirmed that $\mathrm{T} 1$ can eliminate pulmonary function damage (Figure 3(b)) and the formation of pulmonary adenocarcinoma (Figure 4 and Table 1). In addition, western blot showed that the expressions of Cyclin $\mathrm{A}$, and Cyclin B in Tg mice were downregulated following $\mathrm{CM} / \mathrm{T} 1$ treatment as compared with CM/Placebo treatment alone (Figure 7). T1-induced inhibition of Cyclin A and Cyclin B is likely to slow cell cycle progression through the $\mathrm{S}$ and G2/M phases. These results indicate that the proteins involved in the transition from the $S$ to $M$ phase in transgenic mice are suppressed by $\mathrm{T} 1$. The cell cycle blockage may be the critical mechanism for the observed effects following treatment with T1 (Figure 8). This result suggests that one of the mechanisms of T1 inhibition of pulmonary cancer growth is through inhibition of the tumor-activated cell cycle pathway. A previous study [8] demonstrated that T1 treatment significantly reduced the final prostate tumor weight which was also associated with downregulated cancer cell apoptosis, proliferation, Aurora A protein expression, and angiogenesis.

In summary, $\mathrm{T} 1$ significantly reduces lung adenocarcinoma tumor growth. This result may be due to an effect of $\mathrm{T} 1$ on the cell cycle and its pathways. This is the first study to demonstrate that $\mathrm{T} 1$ inhibits pulmonary tumor formation in animal model through down-regulation of cell cycle at $\mathrm{S}$ and G2/M phases. Our research demonstrated that T1 is an efficacious drug candidate for developing a novel class of antipulmonary cancer drugs.

\section{Conflict of Interests}

The authors have declared that there is no conflict of interests.

\section{Authors' Contribution}

Y.-T. Tung and H.-L. Chen contributed equally in this study.

\section{Acknowledgments}

This research was supported in part by Grants NSC98-2313-B-005-012 and NSC-100-2313-B-005-028-MY3 from 
the National Science Council and the Ministry of Education, Taiwan, Republic of China, under the Aiming for Top University (ATU) plan. The funders had no role in study design, data collection and analysis, decision to publish, or preparation of the paper. The coauthor Ms. Yi-Ling Lin was added in the revised version of this paper, because she helped to confirm the pulmonary pathological data and all of the statistical analyses.

\section{References}

[1] Y. C. Ko, C. H. Lee, and M. J. Chen, "Risk factors for primary lung cancer among non-smoking women in Taiwan," International Journal of Epidemiology, vol. 26, pp. 24-31, 1997.

[2] P. Martinez-Moreno, S. Nieto-Ceron, J. Torres-Lanzas et al., "Cholinesterase activity of human lung tumours varies according to their histological classification," Cancinogensis, vol. 27, pp. 429-436, 2005.

[3] J. D. Minna, J. A. Roth, and A. F. Gazdar, "Focus on lung cancer," Cancer Cell, vol. 1, pp. 49-52, 2002.

[4] S. S. Lin, K. C. Lai, S. C. Hsu et al., "Curcumin inhibits the migration and invasion of human A549 lung cancer cells through the inhibition of matrix metalloproteinase-2 and -9 and Vascular Endothelial Growth Factor (VEGF)," Cancer Letters, vol. 285, no. 2, pp. 127-133, 2009.

[5] G. Gasparini, "The rationale and future potential of angiogenesis inhibitors in neoplasia," Drugs, vol. 58, no. 1, pp. 17-38, 1999.

[6] N. Ferrara, "VEGF and the request for tumor angiogenesis factors," Nature Review Cancer, vol. 2, pp. 795-803, 2002.

[7] N. Ferrara and T. Davis-Smyth, "The biology of vascular endothelial growth factor," Endocrine Reviews, vol. 18, no. 1, pp. 4-25, 1997.

[8] Y. Gong, Y. Li, Y. Lu et al., "Bioactive tanshinones in Salvia miltiorrhiza inhibit the growth of prostate cancer cells in vitro and in mice," International Journal of Cancer, vol. 129, no. 5, pp. 1042-1052, 2011.

[9] L. Zhou, Z. Zuo, and M. S. S. Chow, "Danshen: an overview of its chemistry, pharmacology, pharmacokinetics, and clinical use," Journal of Clinical Pharmacology, vol. 45, no. 12, pp. 1345-1359, 2005.

[10] Z. Xia, J. Gu, D. M. Ansley, F. Xia, and J. Yu, "Antioxidant therapy with Salvia miltiorrhiza decreases plasma endothelin-1 and thromboxane B2 after cardiopulmonary bypass in patients with congenital heart disease," Journal of Thoracic and Cardiovascular Surgery, vol. 126, no. 5, pp. 1404-1410, 2003.

[11] X. Wang, S. L. Morris-Natschke, and K. H. Lee, "New developments in the chemistry and biology of the bioactive constituents of Tanshen," Medicinal Research Reviews, vol. 27, no. 1, pp. 133148, 2007.

[12] W. L. Wu, W. L. Chang, and C. F. Chen, "Cytotoxic activities of tanshinones against human carcinoma cell lines," American Journal of Chinese Medicine, vol. 19, no. 3-4, pp. 207-216, 1991.

[13] M. A. Mosaddik, "In vitro cytotoxicity of Tanshinones isolated from Salvia miltiorrhiza Bunge against P388 lymphocytic leukemia cells," Phytomedicine, vol. 10, no. 8, pp. 682-685, 2003.

[14] Y. Song, S. L. Yuan, Y. M. Yang, X. J. Wang, and G. Q. Huang, "Alteration of activities of telomerase in tanshinone IIA inducing apoptosis of the leukemia cells," Zhongguo Zhongyao Zazhi, vol. 30, no. 3, pp. 207-211, 2005.

[15] H. J. Sung, S. M. Choi, Y. Yoon, and K. S. An, "Tanshinone IIA, an ingredient of Salvia miltiorrhiza BUNGE, induces apoptosis in human leukemia cell lines through the activation of caspase3," Experimental and Molecular Medicine, vol. 31, no. 4, pp. 174178, 1999.

[16] Y. Yoon, Y. O. Kim, W. K. Jeon, H. J. Park, and H. J. Sung, "Tanshinone IIA isolated from Salvia miltiorrhiza BUNGE induced apoptosis in HL60 human premyelocytic leukemia cell line," Journal of Ethnopharmacology, vol. 68, no. 1-3, pp. 121-127, 1999.

[17] C. Y. Lee, H. F. Sher, H. W. Chen et al., "Anticancer effects of tanshinone I in human non-small cell lung cancer," Molecular Cancer Therapeutics, vol. 7, pp. 3527-3538, 2008.

[18] I. T. Nizamutdinova, G. W. Lee, J. S. Lee et al., "Tanshinone I suppresses growth and invasion of human breast cancer cells, MDA-MB-231, through regulation of adhesion molecules," Carcinogenesis, vol. 29, no. 10, pp. 1885-1892, 2008.

[19] L. M. Coussens and Z. Werb, "Inflammation and cancer," Nature, vol. 420, no. 6917, pp. 860-867, 2002.

[20] J. J. W. Chen, P. L. Yao, A. Yuan et al., "Up-regulation of tumor interleukin-8 expression by infiltrating macrophages: its correlation with tumor angiogenesis and patient survival in non-small cell lung cancer," Clinical Cancer Research, vol. 9, no. 2, pp. 729-737, 2003.

[21] S. M. Opal and V. A. DePalo, "Anti-inflammatory cytokines," Chest, vol. 117, no. 4, pp. 1162-1172, 2000.

[22] P. L. Yao, M. F. Tsai, Y. C. Lin et al., "Global expression profiling of theophylline response genes in macrophages: evidence of airway anti-inflammatory regulation," Respiratory Research, vol. 6, article 89, 2005.

[23] D. Yuan, Y. N. Pan, W. W. Fu, T. Makino, and Y. Kano, "Quantitative analysis of the marker compounds in Salvia miltiorrihiza root and its phytomedicinal preparations," Chemical and Pharmaceutical Bulletin, vol. 53, no. 5, pp. 508-514, 2005.

[24] J. J. W. Chen, Y. C. Lin, P. L. Yao et al., "Tumor-associated macrophages: the double-edged sword in cancer progression," Journal of Clinical Oncology, vol. 23, pp. 953-964, 2005.

[25] Y. T. Tung, H. L. Chen, C. W. Lai, C. J. Shen, Y. W. Lai, and C. M. Chen, "Curcumin reduces pulmonary tumorigenesis in vascular endothelial growth factor (VEGF)-overexpressing transgenic mice," Molecular Nutrition and Food Research, vol. 55, no. 7, pp. 1036-1043, 2011.

[26] C. C. Yen, C. Y. Lin, K. Y. Chong et al., "Lactoferrin as a natural regimen for selective decontamination of the digestive tract: recombinant porcine lactoferrin expressed in the milk of transgenic mice protects neonates from pathogenic challenge in the gastrointestinal tract," Journal of Infectious Diseases, vol. 199, no. 4, pp. 590-598, 2009.

[27] Y. J. Chen, C. Y. Wu, C. C. Chang et al., "Nuclear Kruppel-like factor 4 expression is associated with human skin squamous cell carcinoma progression and metastasis," Cancer Biology and Therapy, vol. 7, pp. 777-782, 2008.

[28] H. L. Chen, L. C. Wang, C. H. Chang et al., "Recombinant porcine lactoferrin expressed in the milk of transgenic mice protects neonatal mice from a lethal challenge with enterovirus type 71," Vaccine, vol. 26, no. 7, pp. 891-898, 2008.

[29] H. L. Chen, Y. W. Lai, C. S. Chen et al., "Probiotic lactobacillus casei expressing human lactoferrin elevates antibacterial activity in the gastrointestinal tract," BioMetals, vol. 23, no. 3, pp. 543-554, 2010.

[30] T. C. Tsai, W. Lin, S. H. Yang et al., "Granzyme G is expressed in the two-cell stage mouse embryo and is required for the maternal-zygotic transition," BMC Developmental Biology, vol. 10, article 88, 2010. 
[31] Y. J. Chen, C. Y. Wu, J. L. Shen et al., "Psoriasis independently associated with hyperleptinemia contributing to metabolic syndrome," Archives of Dermatology, vol. 144, no. 12, pp. 15711575, 2008.

[32] S. C. Wu, H. L. Chen, C. C. Yen et al., "Recombinant porcine lactoferrin expressed in the milk of transgenic mice enhances offspring growth performance," Journal of Agricultural and Food Chemistry, vol. 55, no. 12, pp. 4670-4677, 2007.

[33] S. Y. Ryu, C. O. Lee, and S. U. Choi, "In vitro cytotoxicity of tanshinones from Salvia miltiorrhiza," Planta Medica, vol. 63, no. 4, pp. 339-342, 1997.

[34] I. T. Nizamutdinova, G. W. Lee, and J. S. Lee, "Tanshinone I suppresses growth and invasion of human breast cancer cells, MDA-MB-231, through regulation of adhesion molecules," Carcinogenesis, vol. 29, pp. 1885-1892, 2008.

[35] L. E. Eberly, J. Ockene, R. Sherwin, L. Yang, and L. Kuller, "Pulmonary function as a predictor of lung cancer mortality in continuing cigarette smokers and in quitters," International Journal of Epidemiology, vol. 32, no. 4, pp. 592-599, 2003.

[36] I. T. Nizamutdinova, G. W. Lee, K. H. Son et al., "Tanshinone I effectively induces apoptosis in estrogen receptor-positive (MCF-7) and estrogen receptor-negative (MDA-MB-231) breast cancer cells," International Journal of Oncology, vol. 33, no. 3, pp. 485-491, 2008.

[37] L. F. Shyur, S. H. Lee, S. T. Chang, C. P. Lo, Y. H. Kuo, and S. Y. Wang, "Taiwanin A inhibits MCF-7 cancer cell activity through induction of oxidative stress, upregulation of DNA damage checkpoint kinases, and activation of p53 and FasL/Fas signaling pathways," Phytomedicine, vol. 18, no. 1, pp. 16-24, 2010 . 


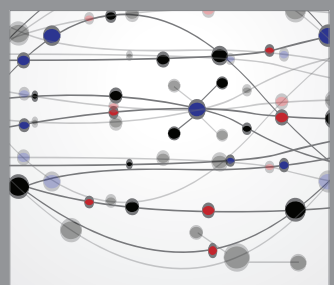

The Scientific World Journal
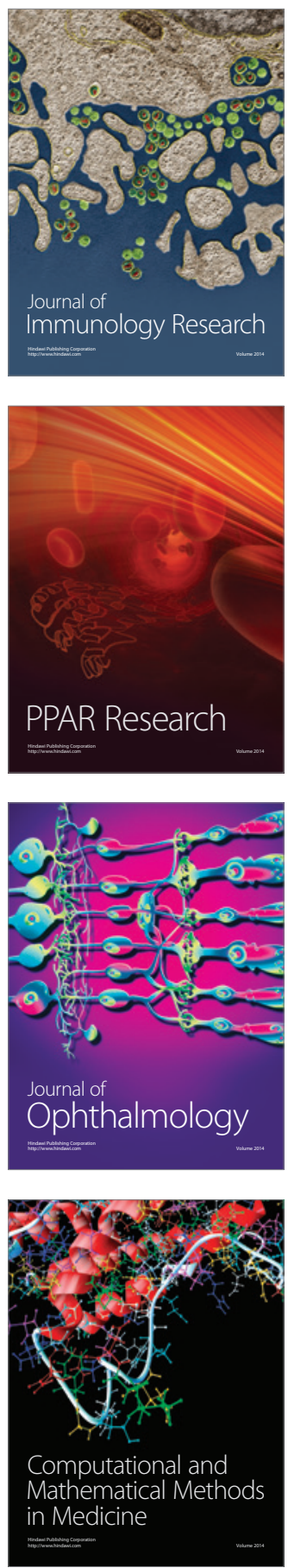

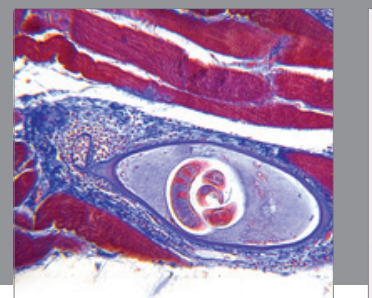

Gastroenterology

Research and Practice
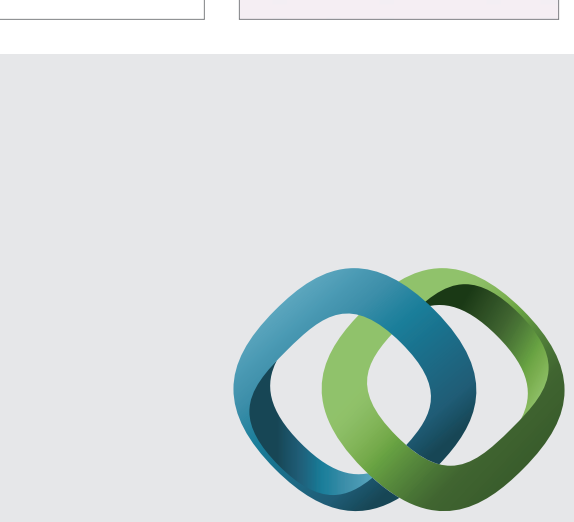

\section{Hindawi}

Submit your manuscripts at

http://www.hindawi.com
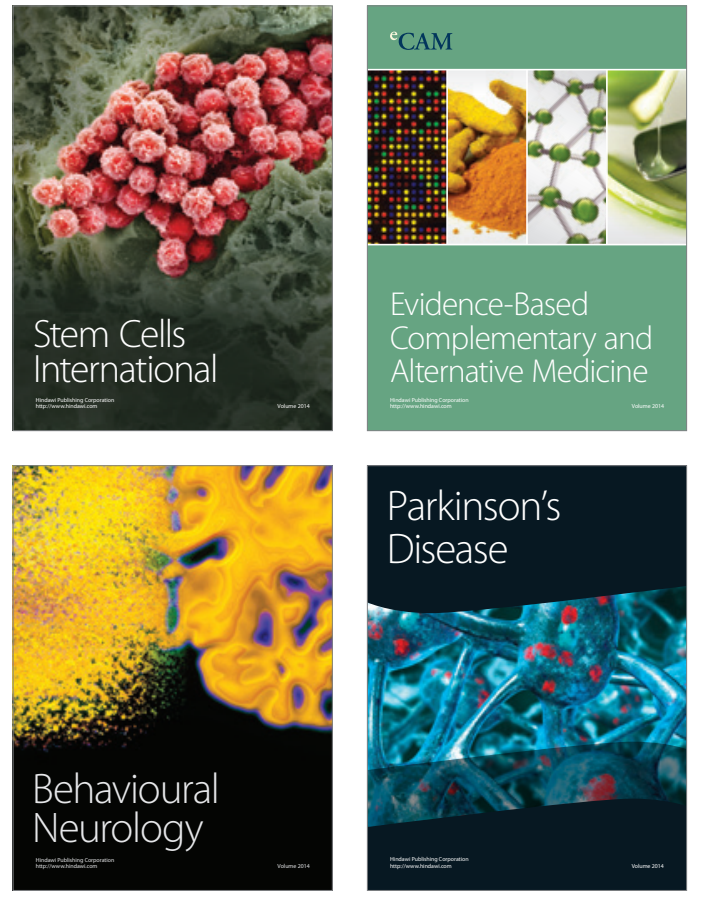
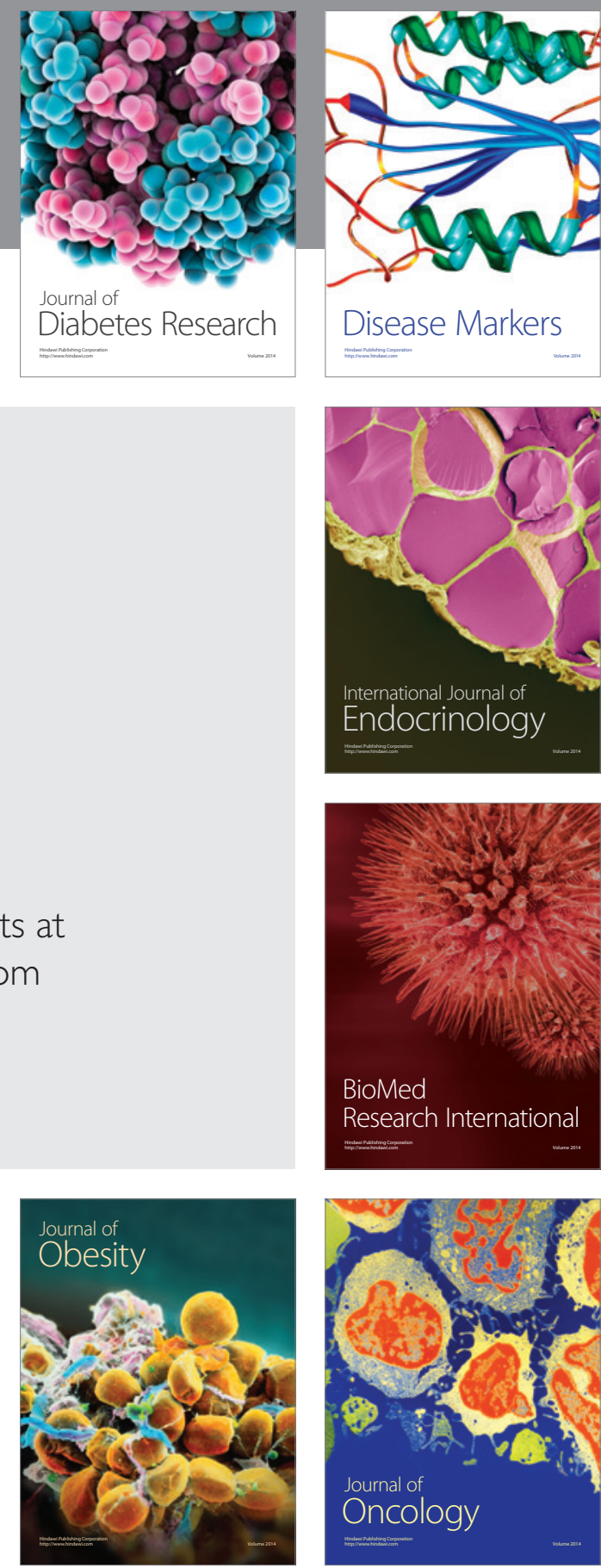

Disease Markers
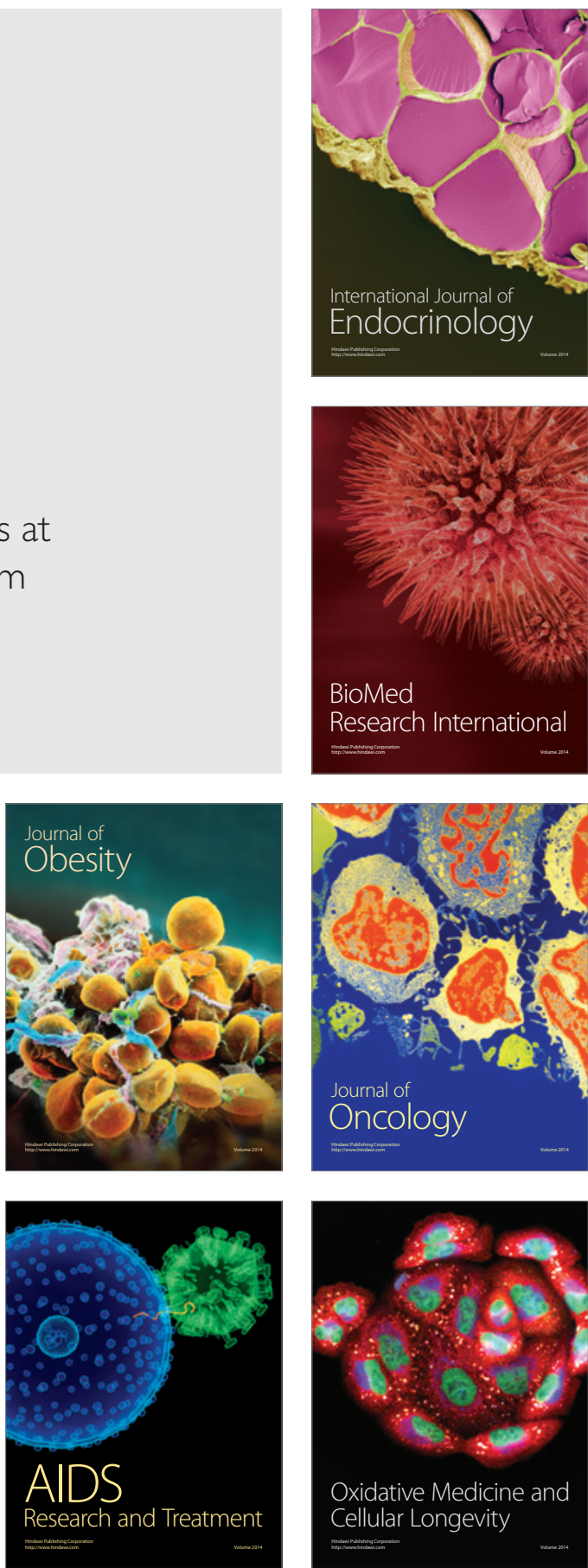